\title{
LA MORADA INTERIOR Y SUS ESPECTROS
}

\author{
María Amoretti Hurtado \\ Universidad de Costa Rica
}

En 1988 y con motivo del IV Simposio Internacional de Literatura organizado por el Instituto Literario y Cultural Hispánico, en San Germán, Puerto Rico, elaboré unas cuantas reflexiones en torno a uno de los cuentarios de Rima de Vallbona: Mujeres y agonías. A partir de esas reflexiones intento ahora adelantar algunas conclusiones sobre el feminismo de esta sobresaliente escritora costarricense, y continuar con el rastreo de lo que cada vez se me va revelando con mayor evidencia: su obra -novelas y cuentarios- es una totalidad que se articula en torno a un mismo eje paradigmático. Es el rastreo de este eje, su evolución y transformaciones, lo que me interesa sobre cualquier otro aspecto, por el momento. Cada una de las obras de Rima de Vallbona son reelaboraciones estéticas de una misma problemática: la culpa asentada en una falta llamada pecado.

En aquella ocasión, también trataba de establecer las codificaciones que hacían de la obra una totalidad dominada por el pesimismo. En ese entonces establecimos que los códigos predominantes eran arquetípicos. Entre ellos sobresalía la díada antagónica del paraíso y el infierno y, obviamente, en medio de ellos los conceptos de pecado, culpa y perdón. O sea, que se trataba del arquetipo escatológico del cristianismo'.

Lo que particularmente llamaba mi atención era el rol tan contradictorio que ofrecía la conciencia como espacio de libertad y al mismo tiempo como prisión, en la mayoría de los personajes femeninos que allí se expresaban. De modo suscinto se estableció que en el cuentario Mujeres y agonías:

1.- Hay un universo que se modela a través de una conciencia femenina.

2.- $\quad$ Que esa conciencia femenina está en busca de su identidad.

3.- Que esa identidad sólo se hace manifiesta en su espacio interior, único ámbito de libertad.

4.- $\quad$ Que la búsqueda es, entonces, degradada, porque la búsqueda de una identidad que no puede instanciarse en el exterior, es absurda desde el mismo momento en que no puede interactuar con el otro.

5.- $\quad Y$ que, por lo tanto, el único refugio protector y libertario se transforma en fosa y la identidad, el ser que viene allí a la vida, está muerta de antemano. 
6.- Si ese espacio interior no es libertario, sino ruta de evasión, entonces la introspección ya no se puede conceptualizar tampoco como proceso de reconstitución del yo y modificación de uno mismo. Podríamos agregar entonces que la introspeción es condición eficiente, pero no suficiente para la constitución del yo.

Las anteriores afirmaciones nos llevaron a concluir que la escritura está caracterizada por un pathos trágico en el más unamuniano de los sentidos, dado que la búsqueda de sí misma termina siempre convirtiéndose en un estado de exilio obligatorio.

Es este pathos trágico el que posibilita -como se verá- una nueva interpretación, ya no para el caso particular del cuentario mencionado, sino en general y para la globalidad de la obra de Rima, la cual ha sido constantemente catalogada como feminista.

En su novela Mundo, demonio y mujer, a pesar de las combinaciones genérico-literarias ( las citaciones que introducen como epígrafes cada uno de sus capítulos, por ejemplo, casi todas tomadas de publicaciones periodísticas o de la literatura) que parecieran testimoniar el carácter político propio de un texto feminista, el pathos unamuniano vuelve a aparecer y esta vez en un nivel explícito, pues la misma protagonista lo cita como personaje de uno de sus sueños:

Como si saliera de una de las fotos suyas tan conocidas (trajeado de negro y con barba semicanosa, espejuelos y sombrero muy peculiar), Unamuno me da una palmadita en la espalda; se podría decir, palmaditas de viejo camarada, y me dice:

- Bien hecho, mujer, muy bien. ¡Adelante y nada de desánimos!.²

Este pathos unamuniano que habíamos identificado ya en 1988 a propósito de Mujeres y agonías, como el implícito factor isotópico por excelencia, reaparece pues como saturando esta obra y muchas otras de Vallbona de un sentimiento de carencia insatisfecho, a pesar de los procesos de autoconcientización de sus personajes femeninos. Esta ansia insatisfecha embarga sus relatos de un pesimismo que se revela en las elocuentes connotaciones de sus títulos: Noche en vela, Las sombras que perseguimos, Cosecha de pecadores, Los infiernos de la mujer, Polvo del camino, Baraja de soledades, etc. En ellos, como en Mujeres y agonías y, ahora, en Mundo, demonio y mujer, la intimidad es un espacio de doble valencia: refugio secreto y clandestino pero sin posibilidad alguna de comunicarse con los otros escenarios del yo. Este espacio es más bien vía de escape, pero... ¿hacia dónde?

La pregunta que me hace la obra de Rima es siempre la misma: si la búsqueda de sí equivale en la mujer a un estado de exilio obligatorio, si la identidad es prisionera de su propia intimidad, ¿qué sentido tiene? ¿Qué sentido tiene una identidad que no tiene salida de sí, relación con el mundo, esperanza de despliege en la relación con los otros?

Esta negativización del espacio interior es ya una confrontación con el papel que la literatura feminista le ha dado al ámbito de la intimidad. La intimidad en la obra de Rima juega un rol muy sui generis, muy diferente, como veremos.

La intimidad en la obra de Rima juega el papel del confesionario, es decir, de la autonegación, de la renuncia de sí misma para el mundo. No es gratuito, a mi juicio, que en el título de la obra, entre la mujer y el mundo quien media es el demonio, signo de la separación. 
En la constitución del yo, dos movimientos del alma parecen imponerse: uno es la necesidad de recogerse y el otro es el de salir de sí. Dentro de lo que su obra enuncia, este último movimiento no tiene posibilidad alguna, de ahí que la unidad quede siempre rota y la sensación de plenitud jamás lograda. Aunque la mujer consigue autoafirmarse en su recogimiento, sigue siendo un ser fragmentario porque ese yo no encuentra su conexión con el mundo. Hay por ello en la obra de Vallbona una cierta fatalidad, una cierta inmovilidad que devela la insuficiencia de la denuncia de las injusticias cometidas contra la mujer, que revela que las elucubraciones más refinadas en búsqueda de lo esencialmente femenino son vanas mientras los hombres no inicien, ellos también su propia revolución, para liberarse de las mismas cadenas.

Me pregunto, por ejemplo, recordando las palabras de Foucault, si no nos hemos engañado todos, hombres y mujeres, asentando el poder en un único sitio, cuando más bien este es una fuerza que se ejerce puntillísticamente, una fuerza que no sabemos quién ni dónde comenzó exactamente, una fuerza que ejerce su control por un impulso autoengendrado que se reproduce a sí mismo y que no se puede atribuir a sujeto alguno, puesto que todos están sujetados, sometidos a ella por igual. Cuando los hombres descubran su autoengaño y el feminismo redefina sus estrategias para procurar el encuentro, entonces, tal vez entonces, los seres humanos encuentren finalmente el camino de su plenitud.

Muchas son las preguntas a las que me incita la lectura de las obras de Rima de Vallbona, porque la buena literatura, aquella que llega para quedarse, no es la literatura que propone respuestas, sino más bien la que formula preguntas. Obra abierta, ambigua, como la buena literatura de hoy, obra actual en la que el feminismo se da más por un sentimiento de solidaridad, que por una profesión de fe.

Mundo demonio y mujer pone de manifiesto que el paradigma feminista debe ser replanteado de otra forma. El texto, saturado por el vacío y la carencia, ilumina, por la lógica del absurdo, una comprensión del feminismo más allá de un movimiento político, inspirado en la lucha por el poder femenino. La consecuencia implícita de este sentido de frustración y de fracaso, de ansia insatisfecha que deja el texto, a pesar de la claridad de conciencia que alcanza la protagonista de su situación socioideológica como sujeto, reformula la cuestión femenina como un planteamiento más bien ontológico, simplemente humano, completamente independiente de las nociones de sexo y aún de género.

En la obra de Rima de Vallbona, la feminidad está recluida a la intimidad e inhibida de la relación, tal como la entiende Martin Buber en su obra ya clásica titulada Yo y Tú; por eso la masculinidad es también una categoría mutilada, ya que desconoce al tú de la palabra primordial. En el mundo ficcional de Rima la única palabra conocida es la del yo-ello y el otro lado del mundo permanece todavía en el misterio.

La escritura femenina se ha planteado y continúa planteándose, mediante la revisión de las subjetividades pervertidas o alienadas, ¿cuál será entonces, vuelvo a preguntarme, la tecnología adecuada para la formación de un sujeto que sea capaz de romper la barrera que impide el encuentro con el otro?

La obra de Rima es, en esa dirección, una vivencia negativa de la intimidad, vía de paso a una "ruta de evasión" despatologizada por la sublimación que la denomina como una ruta hacia la eternidad, hacia el encuentro con el todo, cuando ese encuentro pleno sólo puede ser mediado por el encuentro con el otro simple mortal, como yo, que habita conmigo este mundo. 
Sólo una perspectiva despolitizada y humanista del feminismo, formulado ya no como una conceptualización cultural, sino más bien como una categorización ontológica de lo humano, podría llevarnos a la relación ideal.

Mundo, demonio y mujer es una historia de expoliación que pretende buscar un desenlace feliz, gracias a la final liberación de la mujer que se redescubre a sí misma.

Renata, la protagonista, dice renacer después de liberarse de su tiránico marido y exclama llena de júbilo:

... Renací yo, yo, yo!!! Yo que hacía años yacía muerta en mi morada interior (p. 294)

La semántica misma del nombre de la protagonista, la renacida, pareciera orientarnos hacia una interpretación positiva del destino de esta mujer. No obstante, después de su liberación continúa esa ansia insatisfecha que no logra resolver ni siquiera la perspectiva y la promesa de un amor nuevo. El relato es la saga de una búsqueda incansable; para Renata la vida es "búsqueda incesante de algo que no se sabe qué es, pero se presiente. Y si muriera yo sin encontrarlo?". (p. 290) ${ }^{3}$

Las vicisitudes de la narración alimentan constantemente la espectativa del renacer de la protagonista, impelida, además, por la propia denominación del personaje, como ya se dijo:

¿Será cierta la interpretación freudiana de que los sueños de muerte no representan un final definitivo, sino sólo que una etapa de la vida termina para dar cabida a otra nueva, diferente? Si es así, ¡aleluya!, un nuevo amanecer se anuncia en mi existencia. (p. 253)

Esta promesa implícita va cobrando fuerza también conforme se desarrolla un proceso de concientización interior, reforzado por los diálogos con las otras mujeres, sus amigas, compañeras del dolor y de la soledad que el fracaso amoroso y matrimonial les ha deparado. Por esta razón, cuando por fin Renata toma la decisión de liberarse de ese "monstruo social que llaman matrimonio", como ella misma dice (p. 129), cuando por fin toma la decisión de su divorcio y lo logra, el lector espera la vivencia efectiva de la resurreción de Renata. Pero ella, no logra renacer y el relato se cierra con una frase que no se puede dejar pasar por alto: al escuchar las palabras de una canción que le llega desde lejos y que afirma lo maravilloso que es el mundo, la protagonista exclama a modo de réplica: “ ¡Si lo fuese!, ay, si de veras lo fuese” (p. 320).

Y esta es la última línea de la novela: una exclamación de dolor (ay!) y la expresión de un deseo que sigue permaneciendo insatisfecho, atrapado en el modo subjuntivo (¿subjetivo?) de una frase condicional en la que el sujeto se manifiesta suspirando todavía por sí mismo, mutilado en el ansia insatisfecha de llegar a ser lo que es y en el dolor de no haberlo podido lograr.

No puedo dejar pasar por alto este desenlace porque me recuerda otro; el de una novela que es ya en las letras nacionales una pieza clásica de la literatura feminista y cuya autora ha sido precisamente uno de los campos de estudio de Rima, la académica e investigadora. Me refiero a Yolanda Oreamuno, extraordinario exponente de la literatura de Costa Rica y precoz crítica del machismo de nuestra sociedad patriarcal, de cuya obra Rima se ha ocupado y ha publicado diversas investigaciones. 
La novela de Yolanda en la que estoy pensando es La ruta de su evasión. Como su título parece sugerir, también en ella se da un espacio interior que si bien es refugio, no es un ámbito libertario; se trata más bien de una ruptura con el mundo y de una muerte para el mundo. Sin embargo, del conjunto de personajes femeninos que viven su condición de mujer en esa sociedad de machos, el que cierra la novela la clausura mediante un gesto metafóricamente significativo: la apertura de una ventana. Este hecho resuelve el mundo de oscuridades metonímicas y existenciales que había dominado todo el relato. Es una apertura al mundo, a un mundo que se ofrece radiante, dispuesto a ser vivido con goce. Aurora es el nombre de este personaje, la luz fresca, tenue y tierna de la mañana. El carácter incoativo de la semántica auroral es una resolución de sentido que le da una vuelta de ciento ochenta grados a la tonalidad general que había dominado la novela: el mundo de oscuridad que antecede a este momento de apofansis y hierofanía.

¿Por qué este texto y no otro? ¿Por qué esta diferencia tan radical entre dos textos que emergen del mismo contexto, que comparten desde el punto de vista social e ideológico las mismas condiciones genealógicas de posibilidad? No es que pretenda para ambas obras el mismo final, sino tan sólo explicarme porqué es ese final tan diametralmente opuesto ${ }^{4}$.

Algunos críticos han encontrado en Mundo, demonio y mujer un texto saturado por un aliento de esperanza y positivismo que yo, francamente, no veo por ningún lado.

Por eso, la hipótesis que orienta las elucubraciones interpretativas de este artículo y que ya de alguna manera he adelantado, es la siguiente: la novela de Oreamuno es feminista; la obra de Rima, a pesar de su fachada exterior, no lo es, o al menos no lo es de la misma forma.

Hay que considerar en este sentido el hecho de que media entre ambos textos el extraordinario desarrollo del pensamiento feminista que se ha dado entre 1949, fecha de publicación de la novela de Oreamuno, y 1991, momento de emergencia de la novela de Vallbona.

Mundo, demonio y mujer se escribe no sólo a partir de esos cuarenta años de formulaciones, conceptualizaciones y combates del movimiento feminista, sino también que se elabora en diálogo abierto con sus propias contradicciones e inconveniencias. Esta crítica silenciosa es manejada en dos planos:

a.- $\quad$ En los epígrafes que encabezan cada uno de los veinticuatro capítulos del libro, como el que ofrezco a continuación:

En la Conferencia Nacional de Mujeres que tuvo lugar en Houston se debatió arduamente acerca de los derechos de los homosexuales. Muchos delegados temían que incluir dicho punto en la agenda podría desacreditar por completo el plan nacional tanto a los ojos del público en general como a los del Congreso. Interesa señalar que durante el debate, Betty Frieman, quien por mucho tiempo se opuso a apoyar los derechos de las lesbianas, por temor a dañar el prestigio del Movimiento Feminista, anunció lo siguiente: "Como quien ha crecido en América y ha amado a los hombres -tal vez demasiado-, me ha perturbado este asunto. Sin embargo, debemos apoyar a las mujeres que son lesbianas en sus propios derechos civiles". "El Monitor Feminista, diciembre de 1977." (p. 269) 
b.- $\quad$ En las discusiones del círculo de amigas, todas ellas, mujeres instruidas, relacionadas con el mundo académico, el arte, la literatura y la actualidad social y política:

Aquí venimos, y ya lo hemos dicho, no a escuchar cosas trágicas, sino a encontrar en la compañía de todas y cada una, solaz y descanso a nuestro agotador quehacer de mujeres modernas que a la fuerza se tienen que volver supermujeres...(...)

- En resumen, nos llaman liberadas, pero ahí seguimos en el yugo jooo...robadas y bien jooo...robadas. (p. 142)

En ambos planos se da cuenta del estado actual del movimiento: en los epígrafes, las citas periodísticas hacen un recuento de su evolución, sus logros, sus obstáculos y contradicciones; en las discusiones del círculo de amigas se da cuenta de los resultados, las condiciones y vivencias de las mujeres llamadas liberadas, como se pudo observar en la última cita que hemos transcrito.

La realidad concreta de esas cuatro décadas de pensamiento feminista, podría explicar la diferencia entre ambas novelas y sus "perfecits" o desenlaces. Lo veremos.

No pretenderé en este breve espacio intentar un prolijo examen de la obra, sino aventurarme, a partir de hipogramas claves como los contenidos en el título y en el perfecit -que ya hemos comentado de paso- a establecer una globalización de sentido que tenga la suficiente capacidad explicativa para dar cuenta de su totalidad.

Como hemos afirmado, el eje interdiscursivo que une las diferentes obras de Vallbona es la noción de pecado, núcleo organizador de la escatología cristiana y, en consecuencia, de sus prácticas. Quiero detenerme un poco en esta noción y sus derivaciones porque ella es la razón del fracaso y la frustración sobre la que se asienta el pesimismo de las obras de Rima y, en última instancia, el carácter apolítico del feminismo de sus escritos.

El génesis cristiano más que la historia del comienzo del mundo y del hombre, es la historia del nacimiento del pecado. Por eso saltar de la tópica del Edén a la del Infierno, no significa ningún salto semántico; todo lo contrario, Edén e Infierno son complementarios gracias al nexo que los une y los constituye: la noción de pecado.

El pecado es la historia de una falta, de una caída y de la pérdida de una relación, la relación entre Dios y el Hombre. Esa relación es nominada bajo el término de gracia . Estado de plenitud. Como dijimos anteriormente, el concepto de pecado parece ser el quid que provoca la predominancia de la frustración y de una mutilación irreparable en la conciencia del personaje femenino de Vallbona. Pero no se trata del pecado en términos generales, sino de un tipo específico: el deseo sexual. Por eso Eva es una figura isotópica en muchos de sus escritos y también en éste. El título es evidentemente una deconstrucción de lo que el catecismo católico definía como los tres enemigos del alma: mundo, demonio y carne. La permutación de carne por mujer conlleva ya una definición de lo femenino que, dentro del sintagma en que se encuentra, se relaciona con la lascivia. Los pasajes con respecto a este tema son abundantes en la novela. Obsérvese, por ejemplo, el siguiente:

Es más bien el recuerdo de Antonio y sus noches hinchadas de sexo lo que despierta mi piedad por la gata(...); de nuevo vienen a mi memoria mis torturadas 
noches junto a Antonio y entonces, con mi Eurídice ya en los brazos, experimento una corriente de empatía y de femenina identificación. (p. 47)

El cuerpo femenino es instrumentalizado por el macho por ser el objeto de su deseo. La insistencia en este aspecto es harto redundante en el texto y se relaciona de modo extrañamente complejo con el sentido de culpabilidad en la protagonista.

Según la doctrina cristiana, la liberación del pecado sólo es posible mediante la confesión, práctica que se constituye entonces en una hermenéutica del sí mismo, un desciframiento de la interioridad, en la que pareciera refugiarse una secreta concupiscencia que hay que develar y extirpar.

La carne representa, dentro de la moral cristiana en general, el más importante de todos los pecados. De ahí que las faltas referidas al sexo serán siempre las más perseguidas. El siguiente pasaje tomado de la novela en estudio, ilustra cómo la tarea de identificar y analizar el propio deseo sexual es más urgente que la de analizar cualquier otro tipo de pecado:

- Bueno, hija, ¿pero vos dejás que tu novio te toque..., te manosee...?

- ¿Tocarmeee, manosearmeee? ¿Qué quiere decir usted, Padre?

Una montaña de vergüenzas, desde la primera vergüenza de Eva debajo del manzano (...)

- Explicáme, y cuando te besa, ¿qué sentís muchacha?

- Ideay, un placer...Un placer muy intenso que culebrea por todo mi cuerpo (...)

A salvarte de una vez por todas antes de que sea demasiado tarde, ¡incauta! Acuérdate que será para una eternidad y los besos y manitas de aquí, de este bajo mundo, ¡qué efímeros son! Sálvate antes que sea tarde... (p. 95-96)

El cristianismo es el primero en institucionalizar, explica Foucault ${ }^{5}$, las hermenéuticas del sí mismo. Del principio del conocerse a sí mismo que prevaleció en la cultura grecolatina, con el cristianismo se pasa al "confiesa tus pecados". Con el cristianismo, la tarea de analizar el propio yo se da tan solo para poder confesar, extro-vertir el sí. Una objetivación de este tipo obviamente nunca podría ofrecer más que el lado "oscuro" del sí mismo; por eso en el cristianismo, el descubrir y decir la verdad sobre uno mismo, paradójicamente no tiene otra finalidad que la de renunciar a uno mismo.

El personaje en el que mejor se representa esta tarea de la renuncia de uno mismo es Sor María Marcela, una monja mejicana del siglo XVIII, cuya vida ejemplar hace suspirar a Renata, llena de admiración y sana envidia. En el siguiente pasaje, esta monja, que ha despreciado las ventajas de la riqueza y de la admiración que causa su porte y belleza, encuentra en la autohumillación el mejor camino para agradar a Dios:

(...)la grande inclinación que tengo a los desprecios que sólo ellos son todo mi consuelo y alegría que sólo entonces digo, cuando soy despreciada, o desestimada, o abatida, o reprendida, sólo entonces pienso que me conocen, pero cuando me honran o estiman creo que los tengo engañados y me aflijo temien- 
do que el día del Juicio he de ser espectáculo de irrición (sic) a los demonios(...) (p. 212-213)

En la objetivación del ser, la tecnología por medio de la cual se busca redescubrir el sí es la práctica confesional tal y como la entiende el cristianismo, en la cual la indagación del deseo carnal es la falta en la que más se insiste: “-¡El demonio siempre simulando dichas y placeres para los incautos como vos! Es preciso extirpar, anular todo placer de la carne, hasta el de los sueños.”(p. 117-118).

Por eso Renata "aprendió a doblegar su cuerpo hasta dejarlo manso, lacio, sin ansias de amores" (p. 119). Es tan relevante esta falta, este sistema de interdicciones, que se relaciona también de una forma extraña y compleja con la prohibición verbal:

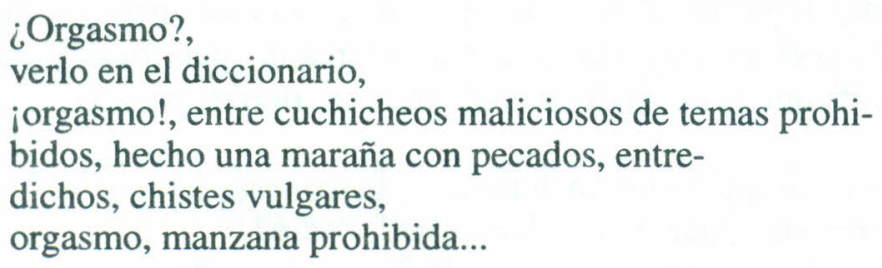

Era muy niña -muchísimo antes de estas confesiones-, cuando Renata comprendió que había una larga lista de palabras que sólo se podían pensar o susurrar. (p. 118)

Posteriormente, continúa Foucault, con el surgimiento del psicoanálisis en el siglo XIX, la sexualidad llega a constituirse en el discurso verdadero sobre uno mismo. La sexualidad es aquello que hay que investigar para llegar a la verdad de uno mismo. El discurso psicoanalítico será en la novela en estudio, la otra forma de examen y comprensión del sí mismo. Pero la diferencia no es muy notoria, en varios aspectos como en el siguiente fragmento en el que aparece nuevamente el motivo del cuerpo femenino:

(...) acabo por adquirir la convición espantosa de que mi sino es un sino fatal, y, entonces, pienso con tristeza en el acierto grande que hubiera sido, el que este cuerpo mío tan lindo...

(...) este cuerpo mío tan lindo y tan desgraciado, no hubiera nacido nunca. Ceñida como estoy dentro de mi kimono de seda negra, al formular este renunciamiento a la vida, me levanto de la hamaca, voy a mirarme en el óvalo alargado del espejo; y allí me estoy un largo rato inundada en el placer doloroso de contemplar mi rostro, tan fino, tan puro de líneas, tan armonioso, tan triste... sí, tan triste y tan perdido para el objeto de sus ansias! (p. 82)

En el psicoanálisis la sexualidad debe ser examinada a fin de descifrar el sí mismo, su verdad y, a partir de esta revelación constituir un nuevo yo. Pero en Renata no hay la constitución de ese nuevo yo, tan sólo la dolorosa aceptación de un yo que se descubre irremediablemente destinado a su soledad. La relación armoniosa con Ricardo por un momento se le presenta a Renata como el final de su búsqueda: 
(...) porque vos hiciste florecer mis espinos, y yo siempre te lo agradeceré. Milagros como éste no ocurren siempre, Ricardo. Quisiera gritarlo por doquier: he vuelto a nacer!, y vos hiciste el milagro. ¿Será éste el final de mi búsqueda? (p. 294)

Pero no es así, puesto que al final, esta relación amorosa perfecta en la que eran "sólo uno, integrados en el misterio del círculo completo, del mandala, de la unión perfecta, total..." (p.294 ), no tiene otra relevancia para Renata que la siguiente:

(...) lo de la frigidez mía fue la barricada tras la que Antonio se escudó para justificar sus aberraciones sexuales. Todo este tiempo experimenté una culpa torturadora, la cual él se gozaba agigantándomela. Es un alivio para mí haberme estremecido de deseos junto a Ricardo...¿No lo comprendes, Laura? si me he enamorado o no es secundario, lo principal es haber tocado fondo con mi identidad de mujer (p. 314)

El descubrimiento de su "normalidad", de su "identidad de mujer", se da con referencia al parámetro sexual, según la define el discurso psicoanalítico; frigidez, aberraciones, son términos propios de ese discurso. Su alienación no es por tanto, muy diferente de la de Antonio, quien también deja escapar, en el poco espacio que le deja la novela, algún asomo de nostalgia por el sentimiento del amor:

Oyéndola escarbar en los recuerdos de estudiantes, se le enternecía la mirada, la voz a Antonio: se le suavizaba el gesto duro de la cara y volvía a ser mágicamente aquel Antonio que la enamoró bajo los faroles del Champs Elysées... (p. 242)

Porque el descubrimiento de su normalidad en términos psicoanalíticos no es suficiente para darle a Renata las pautas de un nuevo yo, la protagonista redefine su búqueda en términos de "algo definitivo, único, la plenitud espiritual de que goza ahora Alberto" (p.315 ). Pero esto no es más que el enmascaramiento de un conflicto interior, de una ínitma contradicción en el proceso de develamiento de su yo atrapado entre dos prácticas discursivas disyuntivas que exigen: una, por su parte, la erradicación del deseo; la otra, por la suya, la liberación de éste. Ambas se trenzan, sin embargo en que fundan un sistema de interdicciones, si bien diferentes, correlativos, pues los dos constituyen el parámetro por el que ambas prácticas miden los grados de sometimiento del sujeto a la normalidad. De una forma o de otra, el sexo en uno, y la sexualidad en el otro, son pretendidamente el oráculo de Delfos, el gran misterio y el vaso que contiene todas las respuestas sobre uno mismo. De ahí que la experiencia de Renata con Ricardo, a pesar de todos sus encantos, no deja de ser más que un experimento con el que ella mide su grado de normalidad social.

Pero el discurso religioso ha de impedirle, una vez más, asumir esa normalidad y la obliga a renunciar a ese renacimiento y, con ello, a renunciar a un posible nuevo yo. Por eso, el renacimiento de Renata no podrá ser ya un renacimiento para el mundo. Al aceptar su yo como un yo destinado a la soledad se implica al mismo tiempo una renuncia al mundo. Por eso el mundo no es tan maravilloso como dice la canción con que se prepara el "cierre" del relato. 
Los dos discursos anteriormente mencionados, el del cristianismo y el del psicoanálisis corresponden a dos prácticas que, si bien son bastante diferenciadas, comparten el mismo punto de partida: la relevancia de la sexualidad y se bifurcan por la promesa que cada una ofrece y por la finalidad que cada una confiere al desciframiento del deseo sexual: la una ofrece, a cambio de la renuncia del deseo, la eternidad ; y la otra, a cambio de la liberación del deseo, la constitución de un yo nuevo para esta vida terrenal.

Son estas dos prácticas y estos dos discursos los que van a cohesionar internamente los diferentes niveles en cada una de las obras de Rima y los que van a otorgar una consistencia de propósito a la obra de Vallbona entendida como una totalidad dirigida por una sola intención, la de la escritora y la del texto. Pero si en esta interdiscursividad ha de haber alguna dominancia, esa sería la de la práctica y el discurso religioso cristiano, dado que de las dos alternativas que de cada uno de esos discursos y prácticas se desprenden respectivamente, la protagonista opta por el de la salvación, la promesa de la trascendencia en un más allá. Opta pues por una relación trascendental.

Además de la presencia de los conceptos de pecado y culpa, hay otros elementos temáticos insistentes en sus obras que se ligan al discurso religioso dominante. En Mundo, demonio y mujer, por ejemplo, los dos seres que alcanzan la plenitud buscada por Renata y a quienes, por eso mismo, ella admira, son dos religiosos: Sor María Marcela y el padre Alberto Casares, ambos seres inicialmente mundanos que luego escogen la vida ascética para realizar el amor ideal, que es el amor místico.

Pero la búsqueda de ese amor místico también es una búsqueda fracasada porque Renata no cree en la vía del encierro monacal y ascético :

La verdad que aprendió aquella tarde en el convento de Barcelona, durante la rencilla e intriga de aquellas religiosas, le demolió a Renata sus veleidades de monja. El resto de su vida tuvo la certeza de que tal escena -humana, sí, pero inaceptabnle en un sacro recinto- había aniquilado la mitad de su ser.

Así, pese a todo, Renata seguía añorando los transportes místicos de su juventud religiosa, aromada de nardos, jazmines, azucenas... (p. 261)

Sin cabida en la vida religiosa, sin vocación para el pecaminoso mundo, Renata se conforma con desenterrar su propio doble espectro: el mundo de su infancia y se satisface con su contemplación, ya que no hay una segunda oportunidad. En ese regreso, la figura de Faustina es el medium por excelencia, pues en ella encuentra la figura materna que nunca tuvo, ya que su madre, la Iglesia y Antonio, son todos uno en la "voz de la autoridad, de la prohibición, del no" (p. 9), son una sola y misma entidad castradora.

Por eso, de todas sus amigas ..."es a Faustina a la que Renata quiere más: a su lado vuelve a recuperar su infancia" (p. 37) "...y es que Faustina tiene la magia de sacar de Renata, ya cuarentona, a la niña de trenzas meladas. A su lado vuelve a escuchar el argentino sonajero, aquel gatito de plata que amaba entrañablemente, pero que un día de desconsuelo, sin saber por qué, lo enterró para siempre." (p. 271)

La infancia es para Renata y en sus propias palabras "paraíso-infancia" (p. 247). Pero Faustina será otra decepción más para Renata. Una renuncia más, obligada por sus principios, "porque cuando creía haber hallado a la hermana de sus sueños infantiles, su casi madre desea- 
da, bastaron unas palabras para borrársela del panorama de su vida y dejarla de nuevo huérfana de afecto, al borde del abismo de su irremediable soledad." (p. 282)

No será Faustina, sino un nuevo momento de desonsuelo el que la lleve, otra vez, a su gatito-sonajero. Hemos dicho que sobre la evolución de ese yo, actúan dos tecnologías de subjetivación: la religiosa cristiana y la psicoanalítica. Pero ambas se alimentan de un tercer discurso. La tradición cristiana deconstruye en varios aspectos la cultura grecolatina (Santo Tomás se encargará de amalgamarlas "cristianizando" en la Edad Media la cultura pagana de Aristóteles) y el psicoanálisis elabora sus nociones más cruciales también a partir de modelos grecolatinos, como son las figuras de Edipo y de Electra, por ejemplo. Esta tercera forma discursiva convierte a Eva en Venus, en quien se reúnen, según el decir de Alberto Casares, "el amor espiritual y la atracción sexual" (p. 312), ya que dentro de este bloque discursivo no hay una tajante contradicción entre esas dos facetas. Así desearía Renata que fuese:

(...) por naturaleza tiende hacia el centro armónico, hacia el mandala donde estaría la integración total de alma/cuerpo, fe/razón, vida/religión, arte/ideología... (p. 59)

Sin embargo, siendo el discurso religioso la nota dominante, para la protagonista de Mundo, demonio y mujer no hay compatibilidad posible entre eros y lo espiritual, a pesar de que dos personajes femeninos intentan mostrarle un camino, una vía y a pesar de que ella, Renata, ha adquirido ya la conciencia de cuál es el origen de sus castraciones.

Uno de esos personajes femeninos que intentan mostrarle una salida es su mejor amiga Faustina, cuyo lesbianismo rechaza de plano Renata en nombre de sus principios y se compadece de que Faustina, a pesar de rechazar los convencionalismos de esos principios, llegue a la edad setentona "sin haber hallado la quietud y paz interior; sin haber saciado la sed de erotismo." (p. 286)

El otro personaje es su hija Gabriela, cuya cosmovisión le causa estupor y admiración al mismo tiempo:

Han de saber una vez por todas que nosotros aplaudiríamos la separación o el divorcio por la felicidad de los dos. David y yo estamos compenetrados y ahora sabemos que nos acoplamos bien hasta en la cama, que juntos vamos a llenar las apetencias de la vida intensa que todos padecemos con mayor o menor intensidad.

Del otro lado de los hilos telefónicos, Renata no pudo evitar ruborizarse y hacerle a Gabriela miles de mudos reproches:

¡Si yo hubiera hablado así a mi madre!,

si yo hubiera tenido algo íntimo con alguno de mis novios, miedo, siempre el miedo agazapado en mis palabras, en mis gestos... (p. 91-92)

Pero para Renata, esos son valores de un mundo que no es el de ella, sino sólo el de las nuevas generaciones y no sabe exactamente cuál de los dos puede ser peor, si la revolución sexual de la nueva generación o la "sarta de principios que pesan" sobre ella. 
Así, ni la opción lesbiana de Faustina, ni la alternativa revolucionaria de Gabriela son soluciones para Renata, porque entre ella y esas respuestas se interpone siempre el mismo sistema de interdicciones: el pecado y la culpabilización correlativa.

Quien lea Mujeres y agonías encontrará ya una idea de la vida como continua reparación de pecados propios y ajenos. Y esta continua reparación se transforma en Mundo, demonio y mujer en la búsqueda de una conciliación con el centro, con la totalidad que es Dios, pues el pecado es siempre una desviación con respecto de ese centro. El mundo se divide en Mujeres y agonías en dos: el afuera de la realidad contrictiva en la que se encuentra la colectividad; y el de adentro, el espacio interior protector del yo. En Mundo, demonio y mujer se continúan elaborando las formas de esa vida interior del adentro, pero con mucho más detalle. En Renata y su autobiografía se reúnen muchos de los personajes femeninos de sus obras anteriores y sus problemáticas, pero al refundirse en un sólo proyecto de vida, los ámbitos en que el yo respira y vive quedan mejor definidos.

Tres espacios o contextos estructuran cada capítulo: lo público que incluye en el texto el acontecer de la colectividad; lo privado, en el que transcurre tanto la vida social de Renata, como la confidencial de la familia y sus relaciones con el cónyuge; y lo íntimo en el que el sueño manifiesta los contenidos todavía indescifrados del yo. Estos tres espacios equivalen a su vez a tres formas de focalización del mundo: una política, otra sociológica y otra psicoanalítica, las cuales se encuentran de alguna manera interpeladas por el código moral de la tradición judeocristiana como dominanate interdiscursiva. Esos tres espacios corresponden también a una articulación explícita y particular en la organización de cada capítulo de la novela: los epígrafes corresponderían a la esfera pública, el desarrollo propio del capítulo a la esfera privada, y el cierre de cada uno de ellos al mundo onírico, siempre intrasferible e indecible de lo íntimo. El título de cada capítulo, que raras veces coincide con los contenidos de los epígrafes, intenta dar un sentido general al capítulo en su totalidad, no obstante, el párrafo onírico final es siempre una enigmática, tanto para el lector como para la misma protagonista.

Para agilizar lo que nos podría tomar varias páginas explicar, proponemos en el siguiente esquema los elementos que integran cada contexto: 


\section{LO PÚBLICO}

Sujeto: la colectividad

Objeto: el cambio (historia, estado actual y contradicciones internas del movimiento feminista)

Escenario: el mundo

\section{LO PRIVADO}

Sujeto: yo, el cónyuge, la familia y el círculo de amigas y amigos

Objeto: la relación (la comunicación)

Escenario: el hogar, el contexto académico y la reunión de amigas

\section{LO ÍNTIMO}

Sujeto: yo y sus espectros

Objeto: el deseo

Escenario: el sueño 
Los dos primeros ámbitos están totalmente reglados, el tercero está tan solo indescifrado. Es el lugar del misterio y del secreto:

El precipitado descenso en el vacío, sin asidero en nada, me da un latigazo de vértigo que me hace despertar sobresaltada, con el corazón palpitante, sudando frío...Temo cerrar los ojos porque ahí adentro, en el misterio de mi oscuridad, continúan la caída y el vértigo. (p. 84)

\section{Es el habitat del deseo:}

En la duermevela seminconsciente, deleitosa, se me quedó flotando una frase inconclusa, la cual repetí hasta despertar: "desearía que... Desearía que..." (p. 11).

Todos los tres ámbitos, no obstante, se comunican aunque el primero parece ser del exclusivo manejo autorial, los títulos incluidos. La relación entre el primero y el segundo resulta la más fuerte de todas y el tercer espacio parece ocultar la interpretación final de los anteriores. En los dos primeros se vierte el yo ideológico, el que maneja la colectividad y el que se manifiesta en las actuaciones y ritos sociales, en su relación con los demás. En el tercero respira un ser agónico, que se debate entre el nacimiento y la muerte: el yo real, que jamás logra ser completamente develado por el texto, ni alcanzado por el autoentendimiento de la misma protagonista.

Al estructurar de esta manera el relato y al resolverlo de manera abierta, sin clausura efectiva, lo que el texto pone en evidencia es, por una parte, el problema de las pluridentidades; y, por otra, el cuestionamiento del principio mismo de la noción de identidad, dada la indescifrable naturaleza de la entidad que se alberga en la morada interior.

A pesar de los esfuerzos de Renata, de lo único que logra liberarse es de su matrimonio, del "infierno de sacrificios, trabajos y carencias", pero no del encierro de idealidad con que el cristianismo de su sociedad patriarcal la ha sitiado. El yo íntimo parece oscuramente contradecir o al menos replicar a los yoes del ámbito público y privado, pero no intenta modificarlos, completamente afectado, como está él también, por los códigos de la moral judeo-cristiana: "la caída y el vértigo" de la autoculpación por un pecado sin remisión como es el pecado original, el pecado de los comienzos del mundo, provocado por Eva, de quien todas las mujeres son sus herederas . Este rasgo neutraliza totalmente cualquier política feminista.

A diferencia de la novela de Yolanda Oreamuno, en la que el yo escindido no es el yo de ninguno de los personajes femeninos, sino el de un archipersonaje que se conforma con la reunión de todas, en la novela de Rima de Vallbona la escisión y la autoconciencia de esta escisión se da en una misma subjetividad. En la novela de Oreamuno el proceso de autoconciencia desborda las individualidades y la transformación atraviesa las diferentes generaciones de mujeres de la novela. Como lo apuntan Flora Ovares, Margarita Rojas et al. en La casa paterna ${ }^{6}$, la experiencia de víctima de algunas de ellas es trascendida en Aurora, quien aprehende de ellas lo que necesita para efectuar el cambio. El proceso se completa entonces en una genealogía de mujeres en la que se destaca "una línea de avance hacia el futuro".

En Mundo, demonio y mujer, esa evolución de la nueva generación de mujeres representada por las hijas de la protagonista (particularmente por Gabriela) y las hijas de sus amigas, 
no es lo suficientemente explotada porque no hay una confianza completa en los beneficios de las actitudes de las nuevas generaciones hacia el sexo y la sexualidad, a pesar de que hay una cierta admiración en ello:

- sigo pagándolo muy caro, al altísimo precio de nuestra felicidad, le dimos al proceso sociohistórico trescientos sesenta grados de vuelta. Fíjate en el cambio tan radical que se ha efectuado en el mundo de la mujer de hoy; tanto, que nuestras hijas están gozando de todos los privilegios que ninguna de nosotras tuvimos. (p. 33)

todas quedaron en silencio pensando en la realidad de sus vidas; envidiando la de sus hijas. (p. 84)

De alguna manera, Renata es entonces la continuación de Aurora y representa una especie de generación de transición, la cual ha vivido las primeras experiencias de la liberación femenina, pero sin poder renunciar a los códigos morales que conforman la base de su personalidad psicoideológica. Esto convierte a la generación de Renata en un ser escindido entre dos mundos, desgarrado por un dilema identitario que es a la vez una disyuntiva moral, ideológica y política irresoluble.

Una vez que el ámbito de lo privado se desintegra en Renata: el matrimonio y la independencia de los hijos, la relación con Faustina, la autoexclusión de Alberto, etc., la protagonista resuelve orientarse hacia la construcción de otro ámbito.

Renata es un sujeto confundido entre sus identidades, como lo sugiere el epígrafe del capítulo XXIII, tomado de Lewis Carroll: "Si no soy la misma, ¿quién soy yo? ¡Ah, esa es la gran incógnita!". (p. 299)

O como exclama la misma protagonista: “¿Sé acaso cuál es mi verdadera identidad cuando digo mi nombre, Renata, Re-nata, Re-na-ta, Re-nada..., la nada repetida...?" (p. 78)

Su incapacidad para encontrarse en ninguna de sus identidades (incluida la íntima, que le permanece indescifrable) hace que se construya ese cuarto ámbito, superestructural, pues desbordaría cualquiera de ellos: el ámbito de lo trascendente.

La construcción de este cuarto ámbito es una necesidad estructural, pues la noción de pecado es la prohibición que inhibe a Renata de su realización en aquellos tres contextos en los que su yo vive fragmentado. La única forma de superar esta escisión irresoluble es un retorno a la completa unidad que es Dios.

La escisión resulta ser una figura clave en el texto y la organización de los mismos capítulos la reproduce. Por otra parte, la acentúa la condición misma de emigrada de Renata, condición esta del extrañamiento que afecta por igual los tres ámbitos, incluido el de manejo autorial que no deja de insertar alguna que otra cita en sus epígrafes relativa al grupo hispánico. Esta vivencia del destierro representa también otro nivel de vacilación identitaria que es muy importante de considerar ya que inserta la contradicción entre otros tipos de contextos que no son los que representan estos tres ámbitos de la persona, sino más bien el de un choque cultural que se amalgama con el choque genérico e intensifica el conflicto del sujeto. Por eso hasta el propio sujeto psicoideológico es un sujeto en crisis y el interlocutor es el yo real que dialoga con ese sujeto a manera de diván psicoanalítico y lo lleva hasta su propio origen. 
El tema del exilio es tema tan relevante en el texto que, además de servirle a la novela de marco publicitario en la contraportada, todo el capítulo XXIII está dedicado a él bajo el título de "La tierra prometida del Norte". Por otra parte, se presenta en el texto también de muy distintas otras maneras, como en el caso de Felicia, la criada mejicana de Renata, en quien ve exacerbados los valores del machismo en la ciega entrega de Felicia por su compañero.

El exilio es el portón negro, que se cierra dejando atrás el ser de nuestro ser, despojo sin asidero ni salida a la luz. Todos estos años eternos, extraña a mí misma, entre rostros palirrubios y el verbo extranjero, me ha enajenado. (p. 20)

Y esta escisión no es sólo la de su experiencia de hispana en Houston:"Desde muy niña, cuando llevaba largas trenzas tilintes y abría muy redondos los ojazos de buey manso y tristón, Renata se había sentido extranjera, enajenada en su propio terruño." (p.21). Por eso en Houston o en su país "de las montañas azules": "Aquí o allá, es igual para mí, sigo enajenada; allá o aquí, el mismo exilio con hambre de eternidad." (p. 21)

La genealogía está, pues, obviamente en otro tiempo y sobre todo en otro espacio, ambos muy remotos, lo cual explica que la protagonista regrese constantemente a su contexto patrio, a sus raíces ancestrales, e inicie una mirada crítica al examinar que los elementos esenciales de la crisis están en los sistemas de representación que convirtieron al yo en sujeto, a través de las específicas técnicas de subjetivación a que fue sometido. Entre los sistemas de representación de su comunidad, comunidad hispánica, la formación discursiva religiosa es la dominante, ella es el núcleo de todos los demás discursos, el punto de referencia inevitable de los otros discursos, sean éstos académicos, progresistas, psicoanalíticos, políticos o sociológicos. El discurso religioso es siempre el punto de referencia obligada en diversidad de aspectos que se pueden aglutinar en dos ejes esenciales:

1.- $\quad$ En la relación del yo consigo mismo.

2.- $\quad$ En la relación del yo con los otros (especialmente con los del otro género).

De modo que en esa interdiscursividad en que se juega el sujeto, el discurso religioso es el que proporciona los elementos, las categorías básicas de estructuración de una visión de mundo, pero sobre todo de la relación del yo con ese mundo, con el exterior. Relación que se caracteriza por la renuncia a que lo obliga una constante presión de los sistemas de interdicción que afectan tanto la palabra como el derecho a ser. Esta situación es la que produce el estado de marginación y de antagonismo con el medio.

Por eso, la felicidad que alcanza Sor María Marcela en su unión mística con Dios o el júbilo del que goza el padre Alberto Casares, parecieran representar para Renata su única salida, la de la eternidad:

Es así que es tesoro inestimable pues es el mismo Dios, el cual Señor he conocido es el centro del alma y más el alma se une con Dios, más en su centro está y tan de asiento y tan firme que me atrevo a decir, y no con temor y con gran libertad que es imposible que esta unión se deshaga(...)y estarse con él amando mutuamente con un mismo y recíproco amor participado del mismo amante dueño, el cual ni un sólo instante suelta al alma de sus amorosos brazos en los 
cuales ella descansa y goza de suma paz con grandísimo deleite, sin gustar de cosa que esté fuera porque todo lo halla adentro. (p. 318)

Por eso Renata se condena a su propio ensimismamiento, a la renuncia de su relación con el otro, hasta la posibilidad del renacer que le ofrece su relación amorosa con Ricardo, porque nada en este mundo está libre del pecado con que sus categorías estructurantes definen su relación con el mundo.

No será, sin embargo, la vida religiosa la vía de acceso a esa trascendencia, ya que hasta en ella el pecado se ha introducido y Renata ha perdido la fe en las instituciones responsables de sus propias castraciones. Su vía de acceso será la de su propio ámbito de intimidad. Por eso, el último sueño, el que constituye el desenlace de la novela, es un regreso al estado de naturaleza de su yo, al paraíso. Después de despedir a Ricardo en una especie de pesadilla de negros nubarrones y de extraños presagios, Renata despierta. Enseguida, en un estado que no es ya ni del sueño ni de la vigilia, se interna en sus "galerías interiores", florecida de primavera, las mismas flores de sus arrebatos místicos juveniles, y luego de traspasar el umbral de un enorme portón de hierro en el fondo del jardín, se encuentra de pronto con el cuarto oscuro de su infancia, pero:

ya no es tan oscuro y ya no me trasmite aquel miedo escalofriante. Al pasar el umbral del portón, voy directo a la tabla que todavía yace sobre el polvo, donde la dejé. La levanto y con las uñas desentierro mi gatito- sonajero. Este se pone a brillar con fulgores de estrella como si me dijese que está intacto, que ni la tierra, ni la humedad, ni los muchos años lograron deteriorarlo. Mi regocijo al redescubrirlo, se hace voz viva en él cuando se pone a dar largos campanilleos de gloria. (p 319)

Hasta aquí sería el desenlace perfecto para superar, al igual que en La ruta de su evasión, el mundo de oscuridad y desencanto de Renata, pero hay que leer las cinco líneas que faltan todavía para terminar la novela. Al igual que en la novela de Yolanda Oreamuno hay una ventana abierta, pero por ella Renata no vislumbra como Aurora la luz de un nuevo día, sino que escucha: "una voz destemplada que canta "It's a wonderful world..." "El mundo es maravilloso..." ¡Si lo fuese!, ¡ay, si de veras lo fuese!”. (p. 320).

De este modo, al igual que en la obra de Oreamuno hay un final abierto, pero saturado de una insuperable melancolía por un mundo al que en definitiva se renuncia sin dejar de desearlo del todo porque el desapego entre yo y el mundo, como dice Buber, hace del yo un yo vacío y quien entra en la relación absoluta no se preocupa ya por nada aislado pues todo está incluido en esa relación, como lo describe Sor María Marcela; sólo que Buber agrega que entrar en relación no es renunciar al mundo, sino establecer el mundo sobre su verdadera base. De ahí que para Buber, no haya propiamente hablando "búsqueda de Dios" porque no hay cosa alguna en la que no se lo pueda encontrar. De igual modo, para él, la única tecnología posible de la subjetividad es la búsqueda del yo en el otro.

He citado insistentemente a Martin Buber, porque el sustrato de misticismo que recorre toda la novela a partir de la inserción de la historia de Sor María Marcela, no es un tema fuera de moda, como lo define Faustina en una de las reuniones de amigas. Es efectivamente una salida ante la crisis actual y Buber es el pensador contemporáneo que mejor representa esta opción. 
Pero el misticismo de Buber es, a diferencia de los místicos clásicos de la literatura cristiana, un misticismo sin renuncia, es un misticismo del ser entero, al cual define como aquel, el único, que puede pronunciar la palabra primordial del yo-tú. Así, desde la perspectiva de Buber, Renata no tendría presente, sólo pasado, pues el presente es para Buber una presencia que implica tres realidades:

1.- $\quad$ El sentimiento de ser acogido (de entrar en una relación).

2.- La confirmación del sentido (de la vida) que no quiere ser interpretado, solo que lo actualicemos.

3.- Este sentido no es el sentido de "otra vida", no es el sentido de un más allá, es el sentido de este mundo de aquí, del nuestro y en esta vida.

Renata no está en ninguna de esas realidades y el gatito-sonajero, símbolo de la fantasía y de lo imaginario, símbolo del comienzo del mundo, del principio del yo, es el único reducto de su ser, ser mutilado por sus propios principios, a los cuales no puede renunciar aunque le sean nefastos -otra vez el pathos unamuniano- porque es muy tarde ya para quien está viviendo "los últimos fríos del otoño".

Hic iacet Renata, una contradicción en los términos, la renacida yace, inmóvil en el mundo de sus sueños, en la eternidad e infinitud de la conciencia, sin poder ni siquiera asomarse a la ventana para ver la luz de un nuevo día. Ciega para el mundo, del cual le llega apenas el rumor de la pálida nota auditiva de "una voz destemplada".

Por eso a Renata no le queda más que renacer en esa otra esfera; deberá recomenzar todo de nuevo pero no sabemos cuándo, ni con qué éxito porque todavía yace en su morada interior, con su doble espectro (o sus demonios), a pesar de los fulgores de estrella y los largos campanilleos de gloria de su gatito-sonajero.

\section{Notas}

1. Posteriormente la Lic. Estébana Matarrita encontraría las mismas estructuras paradigmáticas en el cuentario Los infiernos de la mujer y algo más; su enfoque en relación con estos factores macroestructurantes se diferencia del mío, sin embargo, en que ella los trata como elementos míticos; mientras que yo los inscribo dentro de una religión determinada y sus prácticas concretas, pues mi interés se dirije a tomar muy en consideración el contexto y la comunidad reproducida en esos textos, para hacer un enfoque socioideológico que se articule con el plano psicológico de sus personajes.

2. Rima de Vallbona, Mundo, demonio y mujer. Pág. 237. Todas las citas que presentamos de la novela referida son tomadas de la siguiente edición: Houston: Arte Público Press. 1991. De aquí e n adelante nos limitaremos a señalar el número de página correspondiente, al final de cada cita.

3. Todo el primer capítulo de la novela está dedicado a esta noción de la vida como búsqueda. La enjundia de este capítulo es tal, que ni siquiera lo abordaremos en este trabajo, pues además contiene elementos extraordinarios para una revisión del género autobiográfico, al que nos abocaremos en una próxima publicación.

4. $\quad$ No obstante, tampoco en La ruta de su evasión el salto hacia afuera, hacia el mundo, es un facto. Es tan sólo una posibilidad pero ya esta posibilidad constituye la nota de optimismo suficiente para elevar la tonalidad del relato justo en su desenlace. El salto hacia afuera se textualiza tan sólo con la mirada a través de una ventana que se abre. El hipograma de la casa, el cual recorre y sostiene isotópicamente todo el nivel connotativo de este relato da pie para otras posibilidades, como la puerta, por ejemplo; sin embargo el texto 
elige la ventana y esta elección para representar la apertura hacia el mundo es digna de una cuidadosa reflexión. Recomendamos el comentario que al respecto de la casa como motivo estructurante, aparece en el libro La casa paterna. San José: Ed. de la Universidad de Costa Rica. 1993.

5. Michel Foucault. The technologies of the self. A seminar with Michel Foucaut. Massachusetts: Luther H. Martin. 1983.

6. Op. cit pp. $268-269$

\section{Bibliografía}

Amoreti Hurtado, María. 1989. "Rima de Vallbona: entre la permanencia y el exilio". Revista de Filología y Lingüística de la Universidad de Costa Rica. 15 (2): 23-27. 1989.

Foucault, Michel. 1983. The technologies of the self. A Seminar with Michel Foucault. Massachusetts: Luther H. Mertion.

Oreamuno, Yolanda. 1970. La ruta de su evasión. San José: Editorial Universitaria Centroamericana.

Ovares, Flora et al. 1993. La casa paterna. San José: Ed. de la Universidad de Costa Rica.

Vallbona de, Rima.1991. Mundo, demonio y mujer. Houston: Arte Público Press

1986. Mujeres y agonías. Houston: Arte Público Press. 
